\title{
SILÊNCIO E "MANHAS": FORMAS DE RESISTÊNCIA DO SUBALTERNO EM JANE EYRE
}

\author{
Charles Albuquerque Ponte* \\ Universidade do Estado do Rio Grande do Norte \\ Vanalucia Soares da Silveira ${ }^{* *}$ \\ Instituto Federal de Educação, Ciência e Tecnologia da Paraíba
}

\begin{abstract}
Resumo: Este trabalho tem como objetivo analisar as estratégias de resistência dos subalternos em Jane Eyre (2008), romance de Charlotte Brontë publicado originalmente em 1847, a partir de uma interpretação pós-colonialista. As personagens enfatizadas serão as oriundas da Jamaica, Bertha Mason e seu irmão, Richard, utilizando os modelos de resistência que Ascroft, Griffiths e Tiffin (2010) definem como ab-rogação e apropriação e as que Bhabha (2010) menciona como sly civility (cortesia dissimulada) e mímica. Bertha Mason, a principal representante da subalternidade, faz mais uso da sly civility e da ab-rogação, enquanto Richard Mason utiliza-se mais da mímica e da apropriação, isso porque a colonizada repudia a cultura do centro, ao negar a linguagem europeia, diferentemente do irmão, que procura a imitação, ao apropriar-se do discurso do europeu para garantir seu lugar social, e, desse modo, o hibridismo cultural. Considerada louca e não tendo voz no romance, Bertha Mason desperta a nossa curiosidade acerca da honestidade da narradora, por esta ser branca e seu discurso ser construído a partir de discursos de personagens também brancos, principalmente o de Rochester cujo casamento com a autóctone fora considerado uma empreitada colonial. Dessa forma, somos motivados a compreender a exclusão dos subalternos do mundo simbólico, em correlação com sua procedência racial, cultural e mental, extraindo disso a possibilidade de as cesuras discursivas simbolizarem a opressão e repressão coloniais de uma assujeitação violenta. No entanto, isso não atesta a anulação do sujeito subalterno, pois mesmo censurado, discursivamente, encontra alternativas para resistir às forças colonizadoras.
\end{abstract}

Palavras-chave: Silêncio. Subalterno. Jane Eyre. Pós-colonialismo.

\section{$\oplus \Theta \Theta$}

Br No ND Esta obra está licenciada sob uma Licença Creative Commons.

\footnotetext{
* Possui graduação em Letras Português e Inglês pela Universidade Estadual do Ceará (1999), especialização em Conto de Língua Inglesa no Século XX pela Universidade Federal do Ceará (2001), mestrado em Letras (Inglês e Literatura Correspondente) pela Universidade Federal de Santa Catarina (2003) e doutorado em Teoria e História Literária pela Universidade de Campinas. Atualmente é professor adjunto IV da Universidade do Estado do Rio Grande do Norte. Tem experiência na área de Letras, com ênfase em Literaturas de Língua Inglesa, atuando principalmente nos seguintes temas: Literatura e Cinema Norte-Americanos pós 1960 e teoria literária. E-mail: ca ponte@yahoo.com.br.

** Possui Mestrado em Letras pela Universidade do Estado do Rio Grande do Norte (2013). Atualmente é professor do Instituto Federal de Educação, Ciência e Tecnologia da Paraíba, Campus Sousa. Tem experiência na área de Letras, com ênfase em Literatura Brasileira e Literaturas Estrangeiras Modernas. E-mail: vanaluciaestudosliterarios@hotmail.com.
}

Anu. Lit., Florianópolis, v. 20, n. 1, p. 147-164, 2015. ISSNe 2175-7917 
O trabalho com a palavra lança ao leitor e, especialmente, ao crítico da literatura o desafio de jogar dialeticamente com a semântica ambivalente de um mesmo significante. Um texto favorece mais de uma interpretação, por ser caracteristicamente ambíguo: ele tanto pode ser interpretado por uma lógica monológica, sendo, pois, compreendido como detentor de um significado, uma verdade, uma origem, como pode ser interpretado como um jogo de substituição de sentidos, em um sistema de diferenças. Ambas as interpretações são válidas, aquela não desfavorece esta, já que uma é o suplemento da outra, isto é, a primeira só existe por causa da segunda e vice-versa. Lidar com a palavra é situar-se no entre-lugar, na zona dos interstícios, no terceiro-lugar, onde só há espaço para a indecidibilidade, a aporia (DERRIDA, 2002).

Pela proposta derridiana de desconstrução supramencionada, podemos fazer tanto uma leitura colonialista quanto pós-colonialista sobre questões de raça em Jane Eyre (2008), editado pela primeira vez em 1847 sob o nom de plume Currer Bell, um pseudônimo criado pela autora inglesa Charlotte Brontë (MEYER, 1996). O enredo concentra-se na história da personagem que dá nome ao romance narrado em primeira pessoa e focado em seu processo de formação. A narrativa inicia-se em Gateshead, na casa do único irmão da mãe de Jane Eyre, o senhor Reed, que a adota quando fica órfã. Ali, a menina passa a ser tratada como subalterna, a partir da morte do tio, pela viúva Reed e por seus três filhos: Elisa, Georgiana e John Reed, sendo este último a pessoa que mais a humilha na casa. Nesse espaço, Jane Eyre sofre tortura física e psicológica, por não ter posses, sua mãe tendo sido deserdada após um casamento não aprovado pela família. Contudo, a menina não se cala diante do regime opressor imposto por Gateshead, mostrando-se, assim, uma criança de espírito revolucionário, razão por que a tia a manda para Lowood, um colégio interno de regulamentos e sistemas severos, apenas para mulheres cujas doutrinas moral e religiosa eram usadas para corrigir desvios espirituais. Lá, ela viveu seis anos como aluna e dois como professora, de onde saiu um modelo de autêntica senhora inglesa, pelo gosto refinado e educação à vitoriana, mas à custa da fagulha revolucionária. Sua nova residência será Thornfield, do senhor inglês Edward Fairfax Rochester, onde exercerá o papel de instrutora da menina Adèle, filha de uma dançarina francesa, Céline Varens.

Em Thornfield, Jane Eyre sentia-se livre, não via a diferença de posses como um obstáculo às boas relações sociais, pois não era apenas uma empregada, mas também amiga do patrão e, depois, seu grande amor. A princípio, a vida ali era tranquila, mas logo essa atmosfera vai se perdendo à medida que Jane Eyre vai começando a perceber sinais estranhos 
na mansão, vindos do terceiro andar, como gritos, gargalhadas, resmungos, que eram atribuídos pela governanta e por Rochester à criada Grace Poole. Dia a dia o ambiente vai se tornando mais sombrio, principalmente, quando a figura estranha começa a agir violentamente: primeiro, incendiando o quarto do dono, fato para o qual este age com indiferença; segundo, estrangulando um hóspede misterioso; e, terceiro, rasgando o véu da preceptora, na noite anterior ao dia em que seria seu casamento com Rochester. Mas a tranquilidade na mansão é, finalmente, extinguida no momento desse enlace matrimonial, quando um oficial da lei denuncia o crime de bigamia do noivo, mostrando um documento assinado pelo irmão de sua legítima esposa, o qual está a acompanhá-lo. Trata-se de Richard Mason, a vítima do acidente do estrangulamento. Revelado o segredo e o casamento, pois, impedido, Rochester resolve contar a verdade sobre a existência de sua esposa, a crioula jamaicana Bertha Antoinette Mason. Então, conduz todos à mansão e mostra-lhes sua mulher, presa como um animal em um quarto do terceiro andar, vivendo sob os cuidados da criada Grace Poole. Naquele lugar ele declara a todos os presentes que Bertha Mason é louca.

Jane Eyre deixa Thornfield e, após uma série de peripécias que podem ser omitidas aqui, ela recebe a herança de um tio e, independente, decide voltar à mansão, descobrindo que Bertha Mason havia incendiado a propriedade. No incidente, a esposa morre, mesmo Rochester tentando salvá-la, como fizera com os demais habitantes da casa. Quanto a ele, conseguira sobreviver, todavia ficara temporariamente cego e tivera uma mão amputada. Já não mais residia ali, mas em outra propriedade para onde Jane Eyre se muda para formar família com seu grande amor. Mais tarde, Rochester recupera a sua visão.

Como percebemos, Bertha Mason, embora sem voz na narrativa, e aparecendo de forma marginal nela, assume um papel de destaque, por ser o fio a desatar costuras imperialistas no romance, desenhadas, principalmente, pelo dono da mansão e pela narradora Jane Eyre. A jamaicana atua de forma principal na história que acaba de ser contada, porque grande parte do enredo gira em torno de seu silêncio, da ausência de sua voz. O que sabemos sobre ela é o que nos conta Jane Eyre, Richard Mason, Edward Rochester e, ainda, o hoteleiro que informa a Jane Eyre sobre o incêndio na mansão Thornfield. Pelos discursos deles, podemos relacionar seu silêncio à sua loucura. O que Jane Eyre, a narradora, pôde nos confidenciar sobre Bertha Mason foram apenas os registros de seus ataques neuróticos e de seus atentados provocados na mansão, conforme vivenciou.

Sob uma leitura colonialista, podemos dizer que o par feminino Jane Eyre/Bertha Mason é representado, respectivamente, como: superior/inferior; racional/irracional; boa/má; 
civilizada/primitiva, etc. Essa leitura orienta-se pela metafísica da presença, pelo "eu", procurando mostrar-se como verdade, a origem dos conflitos raciais, relacionando-a com a ideologia do centro, da metrópole, do branco. Já sob uma leitura pós-colonialista, essa ordem é questionada, pois a interpretação realiza-se do lugar do outro, da periferia, do subalterno, visando a desconstruir o entendimento colonialista. Desconstruir não é desmantelar um texto, mas demonstrar que ele em si é desmantelado (MURFIN, 1996, p. 536). Nosso objetivo aqui é ressignificar o discurso do colonizador pela perspectiva pós-colonialista, fazer uma releitura de Jane Eyre (2008), balanceando o discurso do europeu, deslocando o significado instituído por sua ideologia em favor da inclusão dos sentidos construídos pelas vozes sociais (BHABHA, 2010). Reler corresponde, neste caso, a ouvir as elipses históricas; atravessar zonas nebulosas; adentrar terrenos perigosos e relativizar a ordem discursiva (FOUCAULT, 2000; 2009), pois "Se há um silêncio que apaga, há um silêncio que explode os limites do significar." (ORLANDI, 2007, p. 85). Em síntese, a releitura que objetivamos fazer significa atribuir novos sentidos para o silêncio e a loucura, como: 1) o de interdição, o de princípio de exclusão social (FOUCAULT, 2009), ou, ainda, o de carimbo da opressão, da dominação, da rejeição da alteridade (FANON, 1983), e 2) o de discurso da resistência, da subversão colonial. O primeiro sugere que o silêncio de Bertha simboliza a imposição da autoridade colonial sobre o subalterno e que sua loucura pode ter sido consequência da opressão e repressão coloniais sofridas após o casamento, e não causada exclusivamente por fatores genéticos (FOUCAULT, 2009). Já o segundo evidencia que o silêncio e a loucura da caribenha destacam-se como estratégias da colonizada para subverter a ordem colonial. Neste texto, elegemos este último sentido para discutirmos a representação do subalterno na obra em estudo, observando as relações de exploração colonial.

De acordo com Moretti (2003, p. 37), a riqueza colonial é um assunto frequente nos romances sentimentais britânicos do século XIX, uma vez que "As colônias são uma presença verdadeiramente ubíqua: são mencionadas em dois romances em cada três, e as fortunas feitas no exterior chegam a um terço, senão, mais, da riqueza nesses textos".

A Jamaica é um exemplo dessas colônias, por ela enviar as riquezas para mundos distantes, como se verifica em Jane Eyre (2008), através de Bertha Mason, a personagem que atrai o olhar europeu. Nos romances, as histórias das fortunas coloniais costumam ser narradas em forma de comentários rápidos, duvidosos e míticos, como é a história contada por Rochester sobre a origem de seu casamento. 
O que se evidencia nesses romances é, portanto, a relação colonialismo e capitalismo, personagens de um centro industrial atravessando o Atlântico para ocupar territórios vazios e, por conseguinte, explorar suas riquezas, usando, para tal fim, o trabalho escravo. O olho do europeu preenche esses vazios com sua força, com sua ideologia, com sua cultura e torna-se dono das novas terras e de tudo o que nelas existe, inclusive seu povo (BONNICI, 2000, p. 69). Ao fazer isso, o colonizador age como supersujeito, ao considerar-se como centro, enquanto outremiza o nativo, criando, assim, uma relação hierárquica definida pela superioridade da raça branca sobre a não branca (BHABHA, 2010, p. 173-174). Charlotte Brontë cria o personagem Edward Rochester exatamente para exercer esse papel. Ele deixa a Europa, atravessa o Atlântico e chega às Índias Ocidentais, de onde sai rico.

No romance, a narradora não omite a sua preferência por aulas de geografia, outro fato que pode tê-la ajudado a narrar suas memórias, simbolizando ideologicamente a dominação inglesa em diversos outros continentes, que incluía países como a Jamaica. Sob seu ponto de vista, Jane Eyre conta essa história, baseando-se no que ouviu de Rochester no dia em que seria seu casamento com o patrão, quando ele informa em que circunstâncias ocorrera a sua união com a caribenha. Assim, Brontë (2008) constrói uma narrativa mise en abyme. Para a leitura que estamos fazendo, a escolha dessa estrutura textual também pode remeter a uma corroboração da ideologia ocidental (SPIVAK, 2010), porque isso significa dar voz dupla ao europeu, demonstrando a complexidade de suas narrativas, ao passo que anula a voz do colonizado, negando-lhe o direito de, também, narrar o fato de seu ponto de vista.

De acordo com Spivak (2010), analisando a condição do oprimido, o subalterno não tem voz, podendo simplesmente ser representado, e, enquanto representação, seus ideais nunca poderão ser defendidos integralmente, devido, na melhor das hipóteses, aos sujeitos eleitos para falarem por ele deixarem de exercer seu papel de subalternidade ao serem ouvidos, ou, na pior delas, assumirem a função de cúmplices dos interesses internacionais do ocidente. A autora dirige suas críticas aos intelectuais pós-coloniais que têm se solidarizado com o capitalismo e falsificado os reais objetivos da classe de quem são procuradores. A seu ver, até em a voz do subalterno ser representada pelo teórico, sua legitimidade sofre substituição, pois, ao percorrer uma hierarquia que começa das elites locais, passando para as regionais, depois para as nacionais e, por fim, alcançando as internacionais, muitos interesses são confrontados. A logística descrita, de base marxista, mostra que o sujeito representante é um agente individual que faz um agenciamento coletivo, ou seja, ele se coloca no lugar dos homens comuns, mas distorcendo os interesses destes. O representante não passa de um 
“modelo de dissimulação social" (SPIVAK, 2010, p. 36). Por esse prisma, a escritora indiana questiona o lugar do investigador pós-colonial e invalida a possibilidade de o oprimido poder falar.

Desse modo, a partir do discurso europeu, representado pela narradora Jane Eyre, pelo esposo Rochester e pelo hoteleiro de Thornfield, o qual, mesmo sendo de classe média baixa, ganha um pouco de espaço na narrativa no final do romance, contando o episódio da destruição da mansão, demonstraremos a ambivalência do romance, interpretando o silêncio e a loucura de Bertha Mason como alternativas para sair de sua condição subjugada, reconhecida, aqui, como sujeito resistente, ao lado de seu irmão. Com isso, queremos dizer que Charlotte Brontë, ao passo em que nitidamente tenta criar uma hierarquia racial onde mesmo um pobre, mas inglês, tem voz em sua narrativa, enquanto Bertha Mason, jamaicana porém rica, é excluída do mundo simbólico da linguagem, não riscou totalmente a pessoa colonizada em sua escrita.

Nesse sentido, a resistência do subalterno pode ser observada, no romance, por meio de quatro estratégias: a sly civility (a cortesia dissimulada), a mímica, a ab-rogação e a apropriação, sendo as duas primeiras uma denominação de Bhabha (2010) e as duas últimas de Ashcroft, Griffiths e Tiffin (2010, p. 37). Bertha Mason utiliza a primeira e a terceira dessas categorias, enquanto seu irmão Richard Mason lança mão da segunda e quarta delas, isso porque Bertha Mason age muito mais com fingimento, com dissimulação, ao passo que Richard imita o sujeito colonizador. Ela nega a linguagem do colonizador, repudiando a cultura opressora, diferentemente de Richard Mason, imitador e apropriador dos maneirismos discursivos da colônia para garantir seu status quo, através de atitudes permeadas pelo hibridismo cultural.

Os sinais de fingimento de Bertha Mason estão voltados para sua variação comportamental: ora ela está em transes mentais, ora está completamente lúcida; ora ela está calma, ora violenta; ora ela grita, resmunga, gargalha, ora permanece em profundo silêncio. Essa alternância de espírito pode ser compreendida de dois modos: quando Bertha Mason está lúcida, calma e em silêncio, está fingindo que está aceitando a opressão, a repressão, o domínio ocidental. Provavelmente, com isso objetive conquistar a confiança do europeu, fazêlo acreditar que o colonizado é mesmo um sujeito inferior, sem valor e incapaz de mudar a ordem discursiva e colonial para depois agir contra ele. Por outro lado, quando ela está alterada psicologicamente, quando está gritando, resmungando, gargalhando e tramando e praticando crimes, ela está reclamando sua condição de subalternidade de forma explícita. De 
certo modo, Bertha Mason age dissimuladamente, porque a loucura funciona como estratégia para escapar à punição pelas forças coercitivas de poder. Assim, nos limites de sua loucura, a caribenha consegue revidar os crimes coloniais, seu passado e a história de seu povo.

Outra referência à dissimulação da jamaicana é a passagem em que Grace Poole, no dia da espetacularização de Bertha Mason, pede ao patrão para ter cuidado, exatamente no momento em que ele pergunta à empregada se sua paciente "Desta vez ela não tem faca?" (BRONTË, 2008, p. 183), e ela responde: “Oh, nunca se sabe o que ela tem, senhor. É tão dissimulada! Não há mortal que possa prever as suas manhas!” (BRONTË, 2008, p. 183). Bertha Mason é caracterizada como uma pessoa astuciosa, perigosa e imprevisível, revelando a ambiguidade da palavra "manhas", no original "craft" (BRONTË, 2001, p. 250), que tem um significado, assim como no português, de ardil, mas também de habilidade, destreza. De forma inesperada, ela pode atacar seu inimigo, surpreendê-lo com alguma arma e atingi-lo com sua força, como acontece na ocasião em que Rochester se aproxima dela para apresentála aos convidados de seu casamento. De repente, "A louca saltou, agarrou-o ferozmente pela garganta e tentou morder-lhe o rosto.” (BRONTË, 2008, p. 183). Bertha Mason luta com o esposo, investe toda a sua fúria contra ele e tenta libertar-se de seu opressor " [...] no meio dos mais horrendos rugidos e brados e de repelões mais convulsivos” (BRONTË, 2008, p. 183). Ela conspira contra o colonizador no silêncio e age, também, no silêncio. Sua atitude violenta funciona como estratégia colonial para reivindicar lugar social, o direito à personalidade.

De acordo com Andrade (1978, p. 9-10), o colonizado tem o direito à sua própria história, a libertar-se do peso colonial, resgatando sua identidade nacional. Isso porque o subalterno sente-se um parasita do mundo, um sujeito sem origem, sem identidade, uma criatura ambulante (FANON, 1983, p. 82). Esse complexo deriva da civilização branca, da cultura europeia que "impuseram ao Negro um desvio existencial." (FANON, 1983, p. 14). No entanto, não existem fronteiras biológicas entre grupos humanos, pois "As diferenças que há entre nós não se devem em parte a fatores genéticos, em parte a fatores ambientais ou culturais, mas são essencialmente diferenças entre indivíduos, não diferenças entre grupos raciais separados por barreiras" (BARBUJANI, 2007, p. 152).

O que traça divisas entre os humanos não é a raça, mas especificidades relacionadas a cada indivíduo. Entre as supostas diversidades raciais, existem poucas diferenças genéticas. Portanto, não é a cor da pele que define nossa posição na sociedade, sendo as raças apenas uma invenção social. 
A alternância de papéis de Bertha Mason sugere, também, a ambivalência da estratégia colonial. Ao dissimular-se, o sujeito subalterno não troca de lugar com o déspota, ele fica dividido entre dois lugares: o do colonizador e o do colonizado, ou seja, fica ocupando a zona fronteiriça, o entre-lugar cultural, o terceiro espaço. Na realidade, ele não inverte a ordem metafísica, porém mostra que ela precisa ser repensada, respeitando a noção de diferença cultural. Mas isso é muito mais importante, pois, segundo Bhabha (2010), significa a quebra de uma memória mítica de identidades intocadas e a introdução de um novo espaço nas definições culturais com a inclusão do povo nos enredos históricos, isto é, significa a possibilidade de negociação entre culturas.

As aparições de Bertha Mason nos corredores da mansão Thornfield com passos calados durante a noite, enquanto a Inglaterra dorme, representam o movimento cultural, a presença ameaçadora do outro no local europeu, a intimidade intersticial. Seu desejo de abrir portas pode significar seu anseio por romper os limites impostos pelo colonizador ao colonizado, por aterrorizar a autoridade colonial, desafiando a lógica espacial estabelecida por ela. Isso está claro, porque a jamaicana descerra as fechaduras colocadas por aqueles que a oprimem diretamente, como Rochester e Jane Eyre. Para conseguir sair de sua condição escrava, Bertha Mason finge para a empregada que está dormindo ou bêbada e, quando esta se vê vencida pela astúcia da paciente, aquela começa a lutar contra seus opressores. Se a louca isenta sua enfermeira de algum crime, provavelmente, é porque esta não deixa, à sua maneira, de ser uma escrava.

Os crimes contra o branco - o incêndio do quarto de Rochester, o estrangulamento de Richard Mason, o rasgamento do véu de Jane Eyre e o incêndio da mansão Thornfield - são planejados e executados secretamente, usando a estratégia da dissimulação. Ela finge para todos da casa que está dormindo e, enquanto isso, abala a estrutura colonial. Incluímos Richard Mason nessa representação do branco, porque ele é um personagem inclinado para o uso da máscara branca; ele é um negro embranquecido, como diz Fanon (1983).

Richard Mason age como um branco, pensa como um branco e comporta-se como um branco. Ele o imita, apropriando-se de seus costumes, de seus valores, de sua cultura, de suas crenças, ou seja, usa as estratégias da mímica e da apropriação para fazer o revide póscolonial. Richard Mason camufla-se de europeu, ao despersonalizar-se e ao amputar aparentemente sua identidade, assumindo, desse modo, até mesmo para sua irmã, a personagem inventada, o que a leva a violentá-lo. O jamaicano usa essa personagem falsa, possivelmente, para conseguir adentrar o ambiente europeu e conhecê-lo, para, em seguida, 
dar-lhe uma resposta. Se ele revelasse para a irmã sua máscara, o revide poderia ser impossível, uma vez que a mímica, segundo Bhabha (2010, p. 135), tem seu lugar na interdição e seu terreno não é transparente.

Uma prova de que Richard Mason poderia não estar compactuando com a opressão de sua irmã diz respeito à sua viagem inesperada a Thornfield, que representou um golpe para o dono da propriedade, como ele mesmo dissera a Jane Eyre, e, ainda, sua visita ao quarto de Bertha Mason sem a aprovação de Rochester, quando lá estava hospedado. Outrossim, podemos perceber a quebra na camuflagem do caribenho no instante em que ele não segura suas lágrimas ao partir da Inglaterra, deixando, assim, a autóctone sob o domínio do europeu.

A presença de Richard Mason na Europa adquire o sentido de luta pela libertação do subalterno e de ameaça anticolonial. Rochester não esconde sua preocupação, até seu pavor, com o discurso do cunhado. Enquanto ele tinha total controle sobre o discurso da esposa, com relação ao suposto aliado a situação era diferente, haja vista Rochester não ter o domínio patriarcal a seu favor para garantir o domínio colonial sobre seu principal inimigo. Ao passo que Bertha Mason estava "completamente" condenada ao silenciamento, seu irmão significava para o europeu uma grande ameaça, já que este não tinha o poder absoluto para impedir aquele de sustentar outra voz. O discurso é, portanto, o poder do qual Rochester quer se apoderar, a saber, ele é também objeto de desejo do colonizador, como defende Foucault (2009, p. 10).

Podemos verificar o desejo de Rochester de ter o poder do discurso sobre Richard Mason quando, após a partida do estrangeiro para seu país, ao trancar os portões de sua mansão, suspira em tom de súplica: "Prouvera a Deus que isto fosse o fim de tudo!" (BRONTË, 2008, p. 134) como se estivesse a dizer que gostaria de nunca mais sentir a ameaça de ter seu discurso questionado pela voz subalterna. Ao fechar os portões, ele transmite a ideia de que anseia a segregação racial, mas também a separação linguística. Ainda podemos constatar esse desejo de exercer o poder sobre o discurso do outro na conversa que Jane Eyre tem com Rochester:

- O perigo da última noite passou completamente, senhor?

- Não posso garantir enquanto Mason não estiver fora da Inglaterra. Jane, viver para mim - é permanecer numa cratera que um dia pode rebentar e vomitar fogo.

- Mas Mr. Mason parece um homem facilmente dominável. Sua influência sobre ele, senhor, é absolutamente decisiva. Ele jamais o desafiará nem o ofenderá.

- Mas, inadvertidamente, num instante, por uma palavra desavisada, pode me despojar, senão da vida, pelo menos da felicidade.

- Diga-lhe que seja cauteloso, senhor. Comunique-lhe os seus receios e ensine-o a ser prudente.

$[\ldots]$ 
- Se eu pudesse fazer isso, sua ingênua, onde estaria o perigo? Aniquilado num instante. Desde que conheço Mason basta dizer-lhe "Faça isso", para ser obedecido. Mas, neste caso, não lhe posso dar ordens. Não lhe posso dizer: "Cuidado, para não me prejudicar, Richard". Ao contrário: cumpre-me mantê-lo ignorante de que pode me complicar a existência. (BRONTË, 2008, p. 135).

Nesse diálogo, Rochester admite estar refém do discurso de Richard Mason, ao assumir sua incapacidade de impor-lhe o silêncio. Sua consolação é achar que seu cunhado mantém-se na ignorância, alheio à questão da exploração colonial. Nota-se, nessa passagem, a preocupação do europeu com a linguagem, com a forma de trabalhar ideologicamente com as palavras para levar adiante seu projeto colonialista. Jane Eyre acredita que seu patrão é "medalhão" nisso, ao crer na capacidade de ele influenciar facilmente Richard Mason com sua oratória. Ao pensar assim e ao incentivar Rochester a ensinar o estrangeiro a ser prudente, Eyre parece deixar clara sua aprovação à política colonialista. Por outro lado, ela não deixa de ser uma expectadora inocente, por não perceber que Richard Mason é um grande ator do revide pós-colonial, devido a ele estar simplesmente usando a máscara branca.

O irmão de Bertha Mason abandona essa máscara no dia em que seria o casamento de Rochester com Jane Eyre, no momento em que assume para o público europeu sua identidade nativa. Richard Mason volta à Europa para denunciar tanto o crime colonial quanto o crime de bigamia de seu cunhado. Para ter sua voz validada na ordem das leis, o jamaicano vai acompanhado de um advogado e com a posse de um documento que atestava a verdade de seu discurso. Richard Mason tinha consciência de que somente sua voz não seria suficiente para desestabilizar "a verdade" a ser contada pelo déspota. Conforme Spivak (2010, p. 15), dificilmente o subalterno pode falar. E mais difícil, ainda, é ele encontrar os meios para se fazer ouvir.

Entre as duas visitas do irmão a Thornfield, a resistência colonial na mansão continuava sob o comando de Bertha Mason. Quando ela rasga o véu de Jane Eyre e depois atira-o ao chão e pisa-o, seus atos parecem manifestar seu sentimento de revolta contra o despotismo inglês. A imagem do véu rasgado pode ser compreendida como o desejo de o subalterno rasgar o véu de civilidade, e por extensão do cristianismo; dilacerar a ideologia europeia de superioridade racial; denunciar os grandes silêncios e hiatos da História; mostrar seu anseio por dividir espaço com o branco na ordem do discurso. Assim, a divisão do véu pode significar a luta do não branco pela descentralização, pelo questionamento da verdade e pelo desmantelamento dos discursos de homogeneidade cultural. Por ser dividido em dois

\footnotetext{
${ }^{1}$ O conto "Teoria do Medalhão" de Machado de Assis (2001, p. 220-226), narra a história de um pai com experiência no uso de discursos ideológicos para atender às convenções de uma sociedade hipócrita, ensinando seu filho a ser um medalhão nisso, ou seja, campeão em dominar o outro pela palavra.
} 
pedaços, e, não, em muitos, o rasgamento do véu ainda pode simbolizar a bigamia, as duas esposas de Rochester, bem como as duas raças, a branca e a não branca, e a própria relação colonial, a metrópole e a colônia. No que concerne ao arremesso e ao pisoteamento do tecido, os atos podem ser entendidos como o desejo de o oprimido livrar-se das "cangas" impostas pela cultura ocidental e de fazer uma revisão do passado, esmiuçando a semântica de cada significante, empregada pelo homem branco (BONNICI, 2000, p. 31). O objetivo de Bertha Mason seria, portanto, denunciar o projeto imperial inglês de espoliação do Novo Mundo. Consoante Bonnici (2000, p. 54), esse projeto insiste em renovar constantemente ao colonizado a ideia de que o colonizador tem o segredo da História.

Nessa cena, contudo, identificamos rastros de ambivalência. Por que Bertha Mason rasga o véu e isenta Jane Eyre de algum crime? A professora de Adèle seria, de fato, sua rival? Analisando o recurso do espelho é possível inferir que a imagem que Jane Eyre vê refletida no vidro de seu quarto não é a de outra pessoa, senão a dela mesma. Essa imagem seria a repetição daquela que ela vira quando criança no quarto vermelho, onde fora trancafiada pela tia e submetida a um castigo comparado ao de um escravo. O que há, portanto, psicanaliticamente, é uma identificação entre as duas personagens: a Bertha Mason do presente corresponde a Jane Eyre do passado, descrita "como uma 'escrava rebelde' ou uma "escrava revoltada" cujos traumas de criança configuraram-se em loucura ${ }^{2}$ (MEYER, 1996, p. 21). Da mesma forma que Jane Eyre escapa do quarto vermelho através da loucura (GILBERT, 1996, p. 477), Bertha Mason também pode ter encontrado saída para sua condição oprimida pela loucura. Assim, "Bertha não age apenas para Jane; ela também age como Jane" (GILBERT, 1996, p. 493). Embora a autora tenha empregado essa fala para referir-se às questões de gênero no romance, aqui, ela, também, faz-se pertinente.

A ambivalência dessa cena refere-se justamente à ambiguidade da identidade de Jane Eyre na narrativa: ela age como déspota ou como subalterna subversiva? Em certos momentos, ela parece atuar como defensora da condição oprimida, por exemplo, quando não compactua com Rochester a ideia de manter Bertha Mason sob o domínio dele, enquanto os dois passariam a usufruir da riqueza que ela lhe concedera e quando ele the diz que não

\footnotetext{
${ }^{2}$ De acordo com Marcondes Filho (2003, p. 206-219), a loucura resulta da incompetência de o universo familiar não dar conta da pressão social sobre ele, tornando-se, assim, seu instrumento, devido a dilacerar individualidades que nele crescem. A instituição familiar burguesa é responsável por fabricar loucos. Corroborando com o pensamento de Durkheim, ele defende que a loucura é produto da moderna desorganização das estruturas sociais. Em síntese, a loucura é uma produção social.
} 
trocaria sua "inglesinha por todo o serralho do Grão turco!"33 (BRONTË, 2008, p. 167), ao que ela responde:

\begin{abstract}
- Num ambiente de serralho eu não ficaria com o senhor nem um minuto! Portanto não me considere igual a uma escrava. Se tem alguma fantasia deste gênero, vá-se embora, senhor! Vá imediatamente para os bazares de Istambul! E empregue, numa vasta compra de escravas, a soma que parece estar tão empenhado em gastar aqui! - Que faria você, Jane, enquanto eu estivesse ocupado em negociar tantas toneladas de carne e organizar um tão formidável sortimento de olhos negros?

- Eu ficaria me preparando para seguir como missionária e pregar a liberdade das cativas, inclusive as habitantes do seu harém. Arranjaria ser recebida nele e promoveria uma insurreição. E o senhor, poderosíssimo Pachá, se encontraria inerme nas nossas mãos. Não haveria nada neste mundo que fizesse cortar as suas amarras antes do senhor assinar um decreto, e o decreto mais liberal que um déspota já assinou! (BRONTË, 2008, p. 167).
\end{abstract}

Em contrapartida, ao reprovar a comparação com uma escrava (oriental!) feita por Rochester, condição que nunca aceitara, motivo pelo qual ela se revoltara contra Gateshead, e ao mostrar-se a favor da libertação dos negros, expressando seu desejo de lutar como missionária para defender os escravos da exploração humana, Jane Eyre deixa subentendidas duas coisas: a primeira, sua indignação contra o fato de ser escravizada, sendo aristocrata pelo sangue, e o mais importante, sendo branca (SCHWARTZ, 1996, p. 550), e a segunda, sua defesa pela liberdade dos escravos só no papel, ficando resguardada, desse modo, a ideia de escravização ideológica, através do cristianismo.

Já o problema de Bertha Mason é outro: ela era rica, mas passa a ser tratada como escrava em Thornfield. Também, diferentemente de Jane Eyre, Bertha Mason age com dissimulação, o que a inglesa não faz, conforme suas próprias palavras, revidando a tia Reed:

Não sou dissimulada. Se o fosse diria que gosto de você. Mas digo-lhe que não gosto; odeio-a mais do que a qualquer outra pessoa no mundo, com exceção de John Reed. E este livro sobre a mentirosa, você devia dar à sua filha Georgiana, porque ela é quem mente. Eu não. (BRONTË, 2008, p. 26)

Jane Eyre classifica-se como uma pessoa autêntica, corajosa e rebelde. Sua fala demonstra indignação contra aqueles que usam a mentira para relacionar-se socialmente. Quanto à rebeldia de Jane Eyre, ela simboliza a saída da opressão pela violência, a mesma estratégia que o colonizador utiliza para dominar o colonizado (CÉSAIRE, 1978). Nesse ponto, contudo, ela iguala-se a Bertha Mason, já que esta sempre procurou sair de sua condição oprimida pela violência. Não obstante, podemos questionar a autenticidade de Jane Eyre, por exemplo, quando ela finge defender a liberdade do escravo estando, possivelmente, a favor da escravização ideológica, como frisamos acima.

\footnotetext{
3 “one little English girl for the grand Turk's whole seraglio." (BRONTË, 2001, p. 229).
} 
Voltando a Bertha Mason, sua última tentativa de romper as barreiras raciais impostas pelo colonizador é ateando fogo à mansão Thornfield. Ela aproveita o momento em que sua enfermeira está embriagada e rouba-lhe as chaves de sua prisão; analisa a casa silenciosamente, e, depois, começa a incendiá-la. Bertha Mason vai até o aposento que pertencera a Jane Eyre e toca fogo em sua cama, "como se soubesse de tudo e a odiasse", segundo o depoimento do hoteleiro de Thornfield à própria Jane Eyre quando esta volta à propriedade (BRONTË, 2008, p. 266-268). A partir desse discurso, podemos inferir que a jamaicana tinha consciência da realidade colonial e que sua loucura era apenas um meio para ela escapar do domínio europeu. É importante lembrar agora que Bertha Mason "tinha momentos lúcidos, dias, às vezes semanas inteiras - intervalos que enchia me [Rochester] insultando" (BRONTË, 2008, p. 192). Disso, constatamos um impasse na narrativa: se por um lado, Rochester afirma que sua esposa tinha seus momentos de lucidez, por outro, somos levados a pensar na reversão de sua oratória, enxergando a possibilidade de, na verdade, a jamaicana ter momentos de loucura para poder escapar de sua condição oprimida, conforme revela seu comportamento.

A resistência de Bertha Mason culmina com a destruição da residência Thornfield, que sugere metonimicamente a destruição da metrópole. De acordo com Meyer (1996, p. 7; tradução nossa), “O espaço doméstico do lar é ao mesmo tempo um domicílio individual, mas também a sugestão de um espaço doméstico em amplo sentido, como o espaço doméstico da Inglaterra.” A ruína física tem o sentido extensivo de ruína ideológica. Desse modo, o sujeito subalterno, em um único ato, efetua os dois tipos de resistência elencados por Said (2011, p. 328): a primária, que é a reação contra a dominação geográfica, e a secundária, que é a subversão à ideologia e à cultura do colonizador.

Assim, o que se vê em Jane Eyre é uma sucessão de atos subversivos com características próprias de movimentos rebeldes, como as tendências incendiárias. $\mathrm{O}$ fogo aparece no romance como um símbolo da luta social, mas também adquire o sentido particular de referência aos trópicos, à colônia americana em oposição ao gelo do centro imperial. Consoante Gilbert (1996, p. 475; 494), Charlotte Brontë usa consistentemente os pares oposicionais fogo/gelo para caracterizar as experiências de Jane Eyre. Pela lógica suplementar, as atitudes incendiárias de Bertha Mason lembram as da inglesa em Gateshead e em Lowood, mostrando sua rebelião contra o despotismo familiar e religioso, respectivamente. 
A batalha final entre colonizador e colonizado, ou entre branco e não branco, acontece no meio das chamas, detalhe que não é casual. As chamas aqui representam purificação, renovação e, não, o fim. Por isso, a morte de Bertha Mason não pode ser entendida aqui como derrota do minoritário, e a cegueira de Rochester simplesmente como castração, como vitória do oprimido sobre o opressor, compreendida pela substituição de lugar, já que agora quem ficara louco fora este. Outra razão para não se interpretar a perda da visão do europeu como derrota do opressor é o fato de ela ter sido temporária, finalizada quando ele desposou outra mulher, afirmando-se como homem mais uma vez. Nesse sentido, a cegueira de Rochester e a morte de Bertha Mason podem expressar o nonsense colonial, a incerteza no campo da cultura, ou seja, a indecidibilidade quanto à verdade histórica instituída pelo imperialismo (BHABHA, 2010, 192-195). Os dois recursos podem revelar a articulação agonística entre os sujeitos nacionais, as raças branca e não branca, e as culturas nativa e europeia. Além disso, podem mostrar que o espaço social precisa ser interpretado pela lógica suplementar, pelo redesenho histórico, pela visão do entre-lugar.

A resistência de Bertha Mason, portanto, significa que o subalterno pode ter voz social, mesmo sem falar. Através do silêncio, ela pôde romper barreiras raciais e buscar afirmar sua identidade, rasgando as camisas-de-força sociais (SANTOS, 2010, p. 263). De acordo com Wadi (2010, p. 341), as tentativas de transpor as linhas de força e de ultrapassar o saber-poder envolvem o processo de subjetivação do subalterno. Arrebentar as teias imperiais é, pois, uma premissa para o reconhecimento do sujeito nativo.

Igualmente, podemos relacionar o silêncio de Bertha Mason com a estratégia da abrogação definida por Ashcroft, Griffiths e Tiffin (2010). A ausência de sua voz na narrativa pode indicar sua recusa pela língua do colonizador, e, paralelamente, por sua cultura, já que, como afirma Ngugi wa Thiong'o (2011), a língua transporta a cultura e, esta, por sua vez, os valores pelos quais nós nos percebemos e percebemos nosso lugar no mundo. Assim, o silêncio de Bertha Mason sugere sua luta pela descolonização, uma maneira de ela sair do jugo colonial. Sua exclusão da linguagem não a impede de sustentar outro discurso, de responder ao centro, pois "São outros sentidos que ganham existência nesse silêncio. Ou seja, ao silêncio imposto pela censura, ele responde com o silêncio dos 'outros' sentidos que ele constitui em outra região.” (ORLANDI, 2010, p. 85).

O mutismo de Bertha Mason funciona como a linguagem do sujeito deslocado, reclamando o desconforto do não pertencimento, ou seja, da angústia de não pertencer a um lugar definido e de não ter uma identidade. Conforme Bauman (2005, p. 19), 
Estar totalmente ou parcialmente "deslocado" em toda parte, não estar totalmente em algum lugar [...] pode ser uma experiência desconfortável, por vezes perturbadora. Sempre há alguma coisa a explicar, desculpar, esconder ou, pelo contrário, corajosamente ostentar, oferecer e barganhar.

O sujeito deslocado sonha em ter um vínculo nacional, porque deseja ter segurança, a qual é garantida pela afirmação de sua identidade, pelo seu reconhecimento social. Uma vez que o deslocamento causa ao nativo a sensação de alheamento, de desprezo, de incômodo, seu anseio é de libertar-se dessa experiência. Desse modo, a busca pela asseveração da identidade parece um grito de guerra, uma estratégia defensiva: o indivíduo ameaçado e mais fraco ataca uma totalidade maior e mais forte (BAUMAN, 2005, p. 83).

Ainda observamos a ab-rogação em outros aspectos no romance, por exemplo, no modo de Bertha Mason vestir-se e comportar-se, recusando obedecer às convenções sociais, ao decidir não cuidar de sua aparência e agir de forma criminosa em Thornfield. Mas o maior ato de recusa da cultura europeia é o de praticar um sacrifício proposital pelo suicídio, haja vista ter sido ela mesma a responsável por esse ato, conforme relatou o hoteleiro de Thornfield a Jane Eyre. Para executá-lo, Bertha Mason aproveita o estado de embriaguez de sua cuidadora, rouba-lhe as chaves e começa a incendiar sua prisão ${ }^{4}$. Depois de assistir à destruição quase completa do local que simboliza o despotismo inglês, a autóctone se autoimola, dando, assim, a maior prova de não desejar viver de forma subalterna.

Desse modo, a luta de Bertha Mason para afirmar sua identidade está relacionada a todos os crimes que ela cometera em Thornfield. No entanto, como afirma Foucault (2011, p. 275), esses crimes não podem ser vistos apenas "como monstruosidades, mas como a volta fatal do que é reprimido, as pequenas ilegalidades não como as margens necessárias da sociedade, mas como o fulcro da batalha que aí se desenrola." Os atos violentos praticados pela jamaicana, portanto, podem funcionar como instrumento político para sua libertação.

Mesmo impedida de falar, Bertha Mason encontra meios para denunciar a política colonialista do branco. A ausência de sua voz no romance não pode ser entendida simplesmente como interdição, mas também como resistência. Do mesmo modo, a loucura de Bertha Mason não pode ser interpretada só como doença ou efeito da opressão e repressão do colonizador sobre o colonizado, ela, ainda, pode significar uma estratégia do subalterno para escapar de sua condição de inferioridade em relação ao branco e afirmar sua identidade.

\footnotetext{
${ }^{4}$ Uma observação que não pode ser ocultada aqui é a violação das normas vitorianas por Grace Poole, através do consumo de bebida alcoólica, mostrando com isso, mais um ponto ambíguo do texto, que não só o colonizado infringe a conduta moral inglesa, mas o próprio inglês, embora este seja redimido de sua culpa, como fez o hoteleiro com a enfermeira, tentando justificar sua imprudência com a missão árdua de sua profissão.
} 
Através da personagem Bertha Mason, Brontë (2008) comprova que o sujeito subalterno pode falar, ele pode ter voz social. A autora mostra que sua escrita é um "processo duplo de dizer e não dizer, de dizer ao não dizer" (SCHWARTZ, 1996, p. 551). Jane Eyre (2008) é, portanto, um exemplo de obra canônica que não pode ser vista tão somente como instrumento de propagação da ideologia de superioridade da raça branca sobre a não branca, pois do lado dessa interpretação está a de que ela contribui para desmantelar discursos instituídos pelas malhas do poder.

Com a criação de uma personagem de origem caribenha e louca, aparentemente marginal na narrativa, por ser excluída do sistema da linguagem, o texto explode os limites dos significantes loucura e silêncio: a partir do comportamento de Bertha Mason e do procedimento de seu esposo com relação a ela, somos provocados a estranhar a ideia visível de patologia mental e de sua consequente omissão linguística, para, ao seu lado inserirmos as hipóteses de que esses significantes ainda podem acumular os sentidos de produção social e resistência colonial. As "manhas" de Bertha Mason despertam a nossa curiosidade acerca da honestidade da narradora, isso porque Eyre constrói a sua autobiografia exclusivamente a partir de discursos de personagens brancos, principalmente o de Rochester, e, além disso, porque sua voz seria suspeita, devido ao inglês ter uma representação afetiva em sua vida. Dessa forma, somos motivados a compreender a exclusão do subalterno do mundo da palavra, em correlação com sua procedência racial, cultural e mental, extraindo daí a possibilidade de as cesuras discursivas simbolizarem a opressão e repressão coloniais de um sujeito duplamente colonizado: por ser mulher e por ser terceiro-mundista.

\section{Referências}

ANDRADE, M. Prefácio. In: CÉSAIRE, A. Discurso sobre o Colonialismo. Lisboa: Sá da Costa, 1978.

ASHCROFT, B.; GRIFFITHS, G.; TIFFIN, H. The Empire Writes Back. 2.ed. London: Routledge, 2010.

ASSIS, M. Teoria do Medalhão. In: COSTA, F. M. (Org.). Os 100 melhores contos de humor da literatura universal. Rio de Janeiro: Ediouro, 2001. p. 220-226.

BARBUJANI, G. A invenção das raças. São Paulo: Contexto, 2007.

BAUMAN, Z. Identidade. Rio de Janeiro: Zahar, 2005.

BHABHA, H. K. O Local da Cultura. 5.ed. Belo Horizonte: UFMG, 2010. 
BONNICI, T. O pós-colonialismo e a literatura: estratégias de leitura. 21.ed. Maringá: Eduem, 2000.

BRONTË, C. Jane Eyre. Belo Horizonte: Itatiaia, 2008.

DUNN, R. J. (ed.). Jane Eyre. 3.ed. New York/London: W.W. Norton \& Company, 2001.

CÉSAIRE, A. Discurso sobre o Colonialismo. Lisboa: Sá da Costa, 1978.

DERRIDA, J. Plato's Pharmacy. In: . Dissemination. Chicago: The University of Chicago, 1981.p. 61- 171. . A escritura e a diferença. 3.ed. São Paulo: Perspectiva, 2002.

FANON, F. Pele negra, máscaras brancas. Rio de Janeiro: Fator, 1983.

FOUCAULT, M. Vigiar e Punir: nascimento da prisão. 39.ed. Petrópolis, RJ: Vozes, 2011. . A arqueologia do saber. 6.ed. Rio de Janeiro: Forense Universitária, 2000. A Ordem do Discurso. São Paulo: Edições Loyola, 2009.

GILBERT, S. M. Plain Jane's Progress. In: BRONTË, C; NEWMAN, B. (ed.). Jane Eyre. Boston/New York: Bedford, 1996. p. 475-501.

MARCONDES FILHO, C. A produção social da loucura. São Paulo: Paulus, 2003.

MEYER, S. Imperialism at Home: race and Victorian women's fiction. London: Cornell University Press, 1996.

MORETTI, F. Atlas do romance europeu: 1800-1900. São Paulo: Boitempo, 2003.

MURFIM, R. C. Deconstruction and Jane Eyre. In: BRONTË, C.; NEWMAN, B. (ed.). Jane Eyre. Boston/New York: Bedford, 1996. p. 536-545.

ORLANDI, E. P. As formas do silêncio: no movimento dos sentidos. 6.ed. Campinas, SP: Editora da Unicamp, 2007.

RHYS, J. Vasto Mar de Sargassos. Lisboa: Bertrand, 2009.

SAID, E. W. Cultura e Imperialismo. São Paulo: Companhia das Letras, 2011.

SANTOS, N. M. W. Psiquiatria e história cultural: a literatura como fonte e a literatura como objeto. In: WADI, Y. M.; SANTOS, N. M. W. (Orgs.). História e Loucura: saberes, práticas e narrativas. Uberlândia: EDUFU, 2010. p. 253-285.

SCHWARTZ, N. No Place Like Home: The Logic of the Supplement in Jane Eyre. In: BRONTË, C.; NEWMAN, B. (ed.). Jane Eyre. Boston/New York: Bedford, 1996. p. 549583.

SPIVAK, G. C. Pode o Subalterno Falar? Belo Horizonte: UFMG, 2010. 
THIONG'O, N. W. Decolonizing the Mind: the politics of language in African literature. Portsmouth: Heinemann, 2011.

WADI, Y. M. Um lugar (im)possível: narrativas sobre o viver em espaços de internamento. In: WADI, Y. M.; SANTOS, N. M. W. (Orgs.). História e Loucura: saberes, práticas e narrativas. Uberlândia: EDUFU, 2010. p. 331-362.

[Recebido em dezembro de 2014 e aceito para publicação em junho de 2015]

\section{Silence and "craft": resistence forms of the subaltern in Jane Eyre}

Abstract: This paper aims at analyzing the subaltern resistance strategies in Jane Eyre (2008), a novel originally published in 1847 by Charlotte Brontë, from a postcolonial viewpoint. The highlighted characters will be the ones begotten in Jamaica, Betha Mason and her brother, Richard, using the resistance models defined by Ashcroft et al. (2010) as abrogation and appropriation, and by Bhabha (2010) as sly civility and mimicry. Bertha Mason, the main representative of subalternity, makes use more frequently of sly civility and abrogation, whereas Richard Mason uses mimicry and appropriation, since the woman repudiates the center culture, forsaking the European language, unlike her brother, who searches to imitate it, by appropriating its discourse to guarantee his social status, and, therefore, cultural hybridism. Considered mad and having no voice in the novel, Bertha Mason incites the reader curiosity towards the narrator's honesty, the latter being white and whose discourse is constructed from other similarly white characters, mainly Rochester's, who married the autochthonous girl as some kind of colonial enterprise. Thus, one is motivated to understand the subaltern exclusion from the symbolic world, in relation to their racial, cultural and mental precedence, extracting from it the possibility that the discursive cleavage symbolize the colonial oppression and repression of a violent subjugation. However, this does not state the annulment of the subaltern subject, for, even if censored, discursively, s/he finds alternatives to resist the colonizing forces.

Keywords: Silence. Subaltern. Jane Eyre. Postcolonialism.

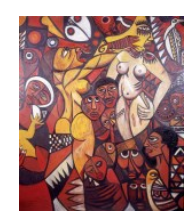

